\title{
QSPR Models for Octane Number Prediction
}

\author{
Jabir H. Al-Fahemi, ${ }^{1}$ Nahla A. Albis, ${ }^{1}$ and Elshafie A. M. Gad ${ }^{1,2}$ \\ ${ }^{1}$ Chemistry Department, Faculty of Applied Science, Umm Al-Qura University, Makah, Saudi Arabia \\ ${ }^{2}$ Petrochemicals Department, Egyptian Petroleum Research Institute, Nasr City, Cairo 11727, Egypt
}

Correspondence should be addressed to Elshafie A. M. Gad; eamgad_99@hotmail.com

Received 31 March 2014; Accepted 7 June 2014; Published 19 August 2014

Academic Editor: D. Sajan

Copyright (C) 2014 Jabir H. Al-Fahemi et al. This is an open access article distributed under the Creative Commons Attribution License, which permits unrestricted use, distribution, and reproduction in any medium, provided the original work is properly cited.

\begin{abstract}
Quantitative structure-property relationship (QSPR) is performed as a means to predict octane number of hydrocarbons via correlating properties to parameters calculated from molecular structure; such parameters are molecular mass $M$, hydration energy $E_{H}$, boiling point $B_{P}$, octanol/water distribution coefficient $\log P$, molar refractivity $M_{R}$, critical pressure $C_{P}$, critical volume $C_{V}$, and critical temperature $C_{T}$. Principal component analysis (PCA) and multiple linear regression technique (MLR) were performed to examine the relationship between multiple variables of the above parameters and the octane number of hydrocarbons. The results of PCA explain the interrelationships between octane number and different variables. Correlation coefficients were calculated using M.S. Excel to examine the relationship between multiple variables of the above parameters and the octane number of hydrocarbons. The data set was split into training of 40 hydrocarbons and validation set of 25 hydrocarbons. The linear relationship between the selected descriptors and the octane number has coefficient of determination $\left(R^{2}=0.932\right)$, statistical significance $(F=53.21)$, and standard errors $(s=7.7)$. The obtained QSPR model was applied on the validation set of octane number for hydrocarbons giving $R_{C_{V}}^{2}=0.942$ and $s=6.328$.
\end{abstract}

\section{Introduction}

Octane rating or octane number is a standard measure of the performance of gasoline fuel. The most common type of octane rating worldwide is the research octane number $(\mathrm{RON})$ and motor octane number (MON). Octanes are a family of hydrocarbon that are typical components of gasoline. The octane rating of gasoline is measured in a test engine and is defined by comparison with the mixture of 2,2,4-trimethylpentane (isooctane) and heptane that would have the same antiknocking capacity as the gasoline fuel under test. For example, gasoline with the same knocking characteristics as a mixture of $90 \%$ isooctane and $10 \%$ heptane would have an octane rating of 90 . The ASTM standard for reporting this measurement is an internal combustion engine in which octane is measured by interpolating between the nearest standards above and below the unknown sample [1]. The procedure is time consuming, involves expensive and maintenance intensive equipment, and requires skilled labour.
A more thorough understanding of the relations between the structure of alkanes and their physicochemical properties and the empirical rules of octane number $(\mathrm{ON})$ dependence on the structure of alkanes are discussed by A. Perdih and F. Perdih [2]. The relation between the structure of hydrocarbons and their octane was studied using a number of topological indices [3]. Nikolaou et al. [4] presented a calculation method that effectively utilizes the compositional data from high-resolution capillary GC analysis and the measured pure and blending RON values of various hydrocarbons, which are widely published. Chung et al. [5] concluded that ridge regression is a viable method for calibration of RON with the NIR data. The prediction results of a ridge calibration model showed more stable prediction performance especially when the spectral baselines were varied. Correlation of the octane number $(\mathrm{ON})$ of heptane and octane isomers with various topological indices was studied by Hosoya [6].

Prediction of gasoline octane numbers using NIR spectrophotometer was studied. Fifty-nine unleaded gasoline samples were analysed spectroscopically as described by 
Kelly et al. [7] to evaluate the chemometrics techniques of principal components regression (PCR) and partial least squares regression (PLS) and to assess the accuracy of the predictions as a function of wavelength range and spectral resolution. They have demonstrated for the obtained data that having a greater resolution is not crucial to the prediction accuracy. Determination of octane numbers of gasoline compounds from their chemical structure by ${ }^{13} \mathrm{C}$ NMR spectroscopy and neural networks, according to Meusinger and Moros [8], demonstrated that the statements from neural network calculations cannot be interpreted in a chemical or physical manner.

Determination of motor gasoline adulteration using FTIR spectroscopy and multivariate calibration was studied [9] using a practical procedure based on the use of density, distillation temperatures, and FTIR analysis along with multivariate calibration. Thirteen peaks of the absorbance at wavenumbers $434,461,484,673,694,1030,1086,1217,1231$, $1460,1497,1606$, and $3028 \mathrm{~cm}^{-1}$ were chosen to perform the multivariate calibration. Artificial neural network (ANN) models have been investigated to determine the research octane number (RON) of gasoline blends by Pasadakis et al. [10]. Graph-theoretical approaches have found application in diverse areas of chemical, industrial, environmental, pharmacochemical, and medical research [11, 12]. Reid et al. [13] and Albahri [3] investigated the structural dependency of octane number using a structural group contribution approach.

The physical and chemical properties of a compound are a function of its molecular structure. Quantitative structureproperty relationship (QSPR) is empirically defined relationship between molecular structure and observed properties. The most comprehensive chemometric data analysis used in quantitative structure-activity and structure-properties relationships (QSAR and QSPR) is explained by Ferreira [14]. QSPR are developed by finding the proper descriptors. It may be constitutional, topological, electrostatic, geometrical, and quantum chemical molecular descriptors. QSPR relationship is most derived by using curve fitting software to find a best predictive model. So the obtained model can be used to estimate the properties of other molecules simply from their chemical structure and without the need of experimental determination or synthesis. Abdel-Moghny et al., Gad, and Gad and Khairou have previous studies on QSPR for critical micelle concentration (CMC), hydrophilic-lipophilic balance (HLB), and crude oil emulsion stability [15-17].

In this study eight descriptors were selected due to their direct physical significances on the behaviour of whole chemical structure of organic hydrocarbon to study QSPR for octane number. The molecular geometry of hydrocarbons was optimized using the AMI, a semiempirical selfconsistent field calculation SCF method for chemical calculations. Molecular mass $M$, hydration energy $E_{H}$, boiling point $B_{P}$, octanol/water distribution coefficient $\log P$, molar refractivity $M_{R}$, critical pressure $C_{P}$, critical volume $C_{V}$, and critical temperature $C_{T}$ are calculated. Different descriptors have been tested by principal component analysis PCA before regression to have a better overview of the variables.

Then multiple linear regression analyses (MLRA) were performed for modelling and estimating the octane number of different hydrocarbon from the calculated descriptors of the chemical structures. The obtained empirical equation sounds acceptable for prediction of the octane number of unknown hydrocarbon.

\section{Methodology}

Experimentally determined octane numbers of the selected hydrocarbons were quoted from Russian Chemical Bulletin [18]. The data sets contain 65 molecules which are divided into two training and validation sets. A training set includes 40 molecules and a validation set includes 25 molecules. The molecular structures were drawn using ChemSketch freeware (Advanced Chemistry Development, Inc. ACD/Labs Release 12.00 (2010)) and then optimized using AM1 semiempirical method. HyperChem 6.03 for windows 8.1. Single point calculations were performed. Each molecule was subjected to molecular mechanics optimization, comparing energies to determine the global minimum energy conformation. Molecular mass $M$, hydration energy $E_{H}$, boiling point $B_{P}$, octanol/water distribution coefficient $\log P$, molar refractivity $M_{R}$, critical pressure $C_{P}$, critical volume $C_{V}$, and critical temperature $C_{T}$ were calculated using ChemOffice Ultra 2004. The eight calculated descriptors are listed in Tables 1 and 2 in addition to the literature of experimental octane number.

\section{Data Processing}

Principal component analysis (PCA) was performed to determine the correlation coefficients matrix of different individual descriptors using statistical computer software XLSTATE version 7.1. Correlation coefficients matrix of the calculated descriptors and the octane number values were determined and so multiple linear regression analysis (MLRA) was carried out using Microsoft Excel 2013. The resulting correlation model for prediction of octane number is in the form of the following equation:

octane number $=\beta_{0}+\beta_{1} X_{1}+\beta_{2} X_{2}+\beta_{3} X_{3}+\beta_{4} X_{4}+\beta_{5} X_{5}$, where $\beta_{0}$ is the intercept (the value of octane number when all $\left.X_{i}=0\right)$ and $\beta_{i}$ is the regression coefficient or slop for variables $X_{i}$ (the calculated descriptors).

\section{Results and Discussion}

4.1. Training Set. The biplot is a visualization technique to investigate the interrelationships between the octane number $(\mathrm{ON})$ and different descriptors in multivariate data. Normally the clusters of observations are illustrated by plotting the scores for the first and second principal components ( $\mathrm{PCl}$ and PC2) shown in Figure 1.

The placing of a parameter on the biplot shows that octane number is influenced by the vectors that lie near it or in the opposite side. However those vectors that lie roughly perpendicular to octane number have low correlation values. The biplot reveals that the parameter such as $C_{p}$ lies close to octane number; that is, this means that $C_{P}$ has +ve correlation with octane number. However the other parameters lie nearly on the opposite direction of octane number. It means that 
TABle 1: Training set of hydrocarbons with their molecular mass $M$, hydration energy $E_{H}$, boiling point $B_{P}$, molar refractivity $M_{R}$, octanol/water distribution coefficient $\log P$, critical pressure $C_{P}$, critical volume $C_{V}$, critical temperature $C_{T}$, the literature octane number $\mathrm{ON}(\mathrm{L})$, and the predicted octane number $\mathrm{ON}(\mathrm{P})$.

\begin{tabular}{|c|c|c|c|c|c|c|c|c|c|c|c|}
\hline & Name & $M$ & $E_{H}$ & $B_{P}$ & $M_{R}$ & $\log P$ & $C_{P}$ & $C_{V}$ & $C_{T}$ & $\mathrm{ON}(\mathrm{L})$ & $\mathrm{On}(\mathrm{P})$ \\
\hline 1 & Cyclopentane & 70.10 & 2.30 & 335.71 & 23.01 & 2.28 & 45.35 & 257.50 & 533.09 & 101.60 & 101.60 \\
\hline 2 & Methylcyclopentane & 84.10 & 2.60 & 353.52 & 27.55 & 2.48 & 38.39 & 312.50 & 549.30 & 89.30 & 81.72 \\
\hline 3 & Ethylcyclopentane & 98.19 & 2.70 & 377.82 & 32.16 & 2.94 & 34.20 & 368.50 & 573.36 & 67.20 & 63.93 \\
\hline 4 & 1,1-Dimethylcyclopentane & 98.19 & 2.80 & 365.11 & 32.03 & 3.28 & 36.07 & 366.50 & 562.90 & 92.30 & 99.99 \\
\hline 5 & 1,3-Dimethylcyclopentane & 98.19 & 2.90 & 370.87 & 32.10 & 2.68 & 32.92 & 367.50 & 564.59 & 79.90 & 75.07 \\
\hline 6 & n-Propylcyclopentane & 112.22 & 3.10 & 401.22 & 36.76 & 3.39 & 30.66 & 424.50 & 595.62 & 31.20 & 32.20 \\
\hline 7 & Isopropylcyclopentane & 112.22 & 3.00 & 387.22 & 36.70 & 3.14 & 30.93 & 418.50 & 579.64 & 81.10 & 69.46 \\
\hline 8 & 1-Methyl-2-ethylcyclopentane & 112.22 & 2.90 & 394.53 & 36.70 & 3.14 & 29.57 & 423.50 & 587.41 & 57.60 & 64.33 \\
\hline 9 & 1,1,3-Trimethylcyclopentane & 112.22 & 3.10 & 382.16 & 36.58 & 3.48 & 31.07 & 421.50 & 577.52 & 81.70 & 93.91 \\
\hline 10 & 1,2,3-Trimethylcyclopentane & 112.22 & 3.00 & 387.77 & 36.65 & 2.89 & 28.54 & 422.50 & 579.05 & 89.20 & 81.07 \\
\hline 11 & Isobutylcyclopentane & 126.24 & 3.33 & 410.26 & 41.30 & 3.60 & 27.88 & 474.50 & 601.33 & 33.40 & 42.51 \\
\hline 12 & 1,1,2,4-Tetramethylcyclopentane & 126.24 & 3.27 & 398.75 & 41.13 & 3.69 & 27.04 & 476.50 & 591.36 & 96.20 & 96.97 \\
\hline 13 & Methylpropane & 58.12 & 2.77 & 276.39 & 20.15 & 1.92 & 39.36 & 253.50 & 433.76 & 102.10 & 103.79 \\
\hline 14 & n-Pentane & 72.15 & 3.16 & 319.19 & 24.81 & 2.63 & 34.68 & 315.50 & 484.56 & 61.80 & 54.63 \\
\hline 15 & Methylbutane & 72.15 & 3.04 & 303.37 & 24.76 & 2.38 & 35.01 & 309.50 & 464.67 & 93.00 & 88.61 \\
\hline 16 & n-Hexane & 86.18 & 3.50 & 344.72 & 29.41 & 3.09 & 31.07 & 371.50 & 511.91 & 31.00 & 32.82 \\
\hline 17 & 2-Methylpentane & 86.18 & 3.35 & 329.44 & 29.36 & 2.83 & 31.35 & 365.50 & 493.31 & 73.40 & 70.56 \\
\hline 18 & 3-Methylpentane & 86.18 & 3.30 & 329.44 & 29.36 & 2.83 & 31.35 & 365.50 & 493.31 & 74.50 & 73.09 \\
\hline 19 & 2,2-Dimethylbutane & 86.18 & 3.22 & 319.21 & 29.23 & 3.18 & 31.74 & 360.50 & 486.30 & 91.80 & 99.13 \\
\hline 20 & 2,3-Dimethylbutane & 86.18 & 3.23 & 313.83 & 29.30 & 2.58 & 31.63 & 359.50 & 473.98 & 104.30 & 105.65 \\
\hline 21 & n-Heptane & 100.20 & 3.86 & 369.34 & 34.01 & 3.54 & 28.00 & 427.50 & 537.33 & 0.00 & 10.17 \\
\hline 22 & 2-Methylhexane & 100.20 & 3.69 & 354.60 & 33.96 & 3.29 & 28.23 & 421.50 & 519.91 & 46.40 & 49.65 \\
\hline 23 & 3-Methylhexane & 100.20 & 3.62 & 354.60 & 33.96 & 3.29 & 28.23 & 421.50 & 519.91 & 52.00 & 53.19 \\
\hline 24 & 2,2-Dimethylpentane & 100.20 & 3.51 & 344.74 & 33.83 & 3.63 & 28.57 & 416.50 & 513.62 & 92.80 & 81.56 \\
\hline 25 & 2,3-Dimethylpentane & 100.20 & 3.46 & 339.54 & 33.90 & 3.04 & 28.48 & 415.50 & 501.81 & 91.10 & 91.74 \\
\hline 26 & 2,4-Dimethylpentane & 100.20 & 3.50 & 339.54 & 33.90 & 3.04 & 28.48 & 415.50 & 501.81 & 83.10 & 89.72 \\
\hline 27 & 3,3-Dimethylpentane & 100.20 & 3.41 & 344.74 & 33.83 & 3.63 & 28.57 & 416.50 & 513.62 & 80.80 & 86.62 \\
\hline 28 & 2-Methylheptane & 114.23 & 4.05 & 378.87 & 38.56 & 3.75 & 25.56 & 477.50 & 544.69 & 21.70 & 27.54 \\
\hline 29 & 3-Methylheptane & 114.23 & 3.97 & 378.87 & 38.56 & 3.75 & 25.56 & 477.50 & 544.69 & 26.80 & 31.59 \\
\hline 30 & 4-Methylheptane & 114.23 & 3.95 & 378.87 & 38.56 & 3.75 & 25.56 & 477.50 & 544.69 & 26.70 & 32.60 \\
\hline 31 & 2,2-Dimethylhexane & 115.24 & 3.83 & 369.36 & 38.43 & 4.09 & 25.85 & 472.50 & 539.01 & 72.50 & 62.86 \\
\hline 32 & 2,3-Dimethylhexane & 114.23 & 3.75 & 364.35 & 38.51 & 3.49 & 25.77 & 471.50 & 527.72 & 71.30 & 74.42 \\
\hline 33 & 2,4-Dimethylhexane & 128.26 & 4.15 & 388.25 & 43.11 & 3.95 & 23.43 & 527.50 & 551.88 & 65.20 & 51.35 \\
\hline 34 & 2,5-Dimethylhexane & 128.26 & 4.26 & 388.25 & 43.11 & 3.95 & 23.43 & 527.50 & 551.88 & 55.50 & 45.78 \\
\hline 35 & 3,3-Dimethylhexane & 128.26 & 4.04 & 369.36 & 38.43 & 4.09 & 25.85 & 472.50 & 539.01 & 75.50 & 70.74 \\
\hline 36 & 3,4-Dimethylhexane & 128.26 & 4.01 & 364.35 & 38.51 & 3.49 & 25.77 & 471.50 & 527.72 & 76.30 & 81.21 \\
\hline 37 & 2-Methyl-3-ethylpentane & 114.23 & 3.61 & 364.35 & 38.51 & 3.49 & 25.77 & 471.50 & 527.72 & 87.30 & 81.51 \\
\hline 38 & 3-Methyl-3-ethylpentane & 114.23 & 3.51 & 369.36 & 38.43 & 4.09 & 25.85 & 472.50 & 539.01 & 80.80 & 77.62 \\
\hline 39 & 2,2,3-Trimethylpentane & 114.23 & 3.58 & 354.62 & 38.38 & 3.84 & 26.06 & 466.50 & 521.58 & 109.60 & 104.84 \\
\hline 40 & 2,3,4-Trimethylpentane & 114.23 & 3.56 & 349.50 & 38.45 & 3.24 & 25.98 & 465.50 & 510.09 & 102.70 & 114.95 \\
\hline
\end{tabular}

these parameters are -ve correlated to octane number. Both the +ve and the -ve are significant correlation.

The relative importance of the descriptors can be confirmed by looking at the correlation matrix shown in Table 2. The higher the correlation coefficient is significant values regardless its sign positive or negative.

Eight descriptors combinations have been tested by multiple linear regression analysis for 40 molecules of octane number values of hydrocarbons. The squared correlation coefficient (or coefficient of multiple determination), also called the $R$-squared of the equation, is denoted as $R^{2}$. It measures the explanatory power of the regression equation. It falls in the range of 0 to 1 , where 0 means the regression accounts for none of the variation and 1 means the relationship was deterministic and the regression accounts for all of the variation. Coefficient of determinations, $R^{2}$, is found to 
TABLE 2: Correlation coefficients matrix of the selected descriptors.

\begin{tabular}{lcccccccc}
\hline & $M$ & $E_{H}$ & $B_{P}$ & $M_{R}$ & $\log P$ & $C_{P}$ & $C_{V}$ & $C_{T}$ \\
\hline$M$ & 1.00 & & & & & & & \\
$E_{H}$ & 0.62 & 1.00 & & & & & \\
$B_{P}$ & 0.83 & 0.26 & 1.00 & & & & \\
$M_{R}$ & 0.98 & 0.66 & 0.82 & 1.00 & & & \\
$\log P$ & 0.85 & 0.76 & 0.64 & 0.87 & 1.00 & & & \\
$C_{P}$ & -0.82 & -0.87 & -0.51 & -0.87 & -0.84 & 1.00 & & \\
$C_{V}$ & 0.95 & 0.80 & 0.71 & 0.98 & 0.91 & -0.95 & 1.00 & \\
$C_{T}$ & 0.67 & -0.04 & 0.95 & 0.63 & 0.44 & -0.23 & 0.47 & 1.00 \\
On(L) & -0.25 & -0.45 & -0.44 & -0.29 & -0.35 & 0.33 & -0.34 & -0.32 \\
\hline
\end{tabular}

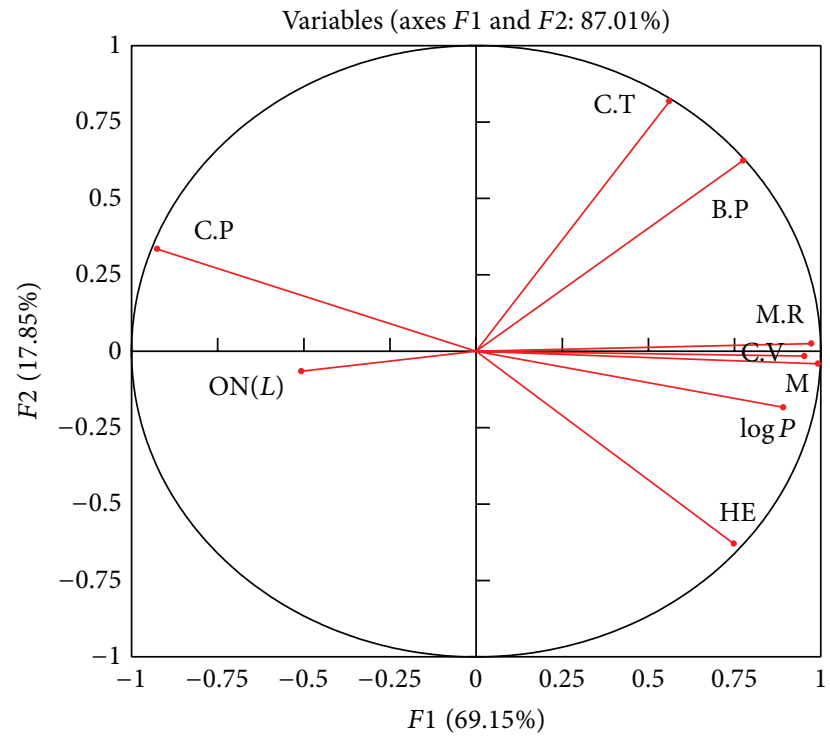

FIGURE 1: The biplot shows the intercorrelation of different descriptors.

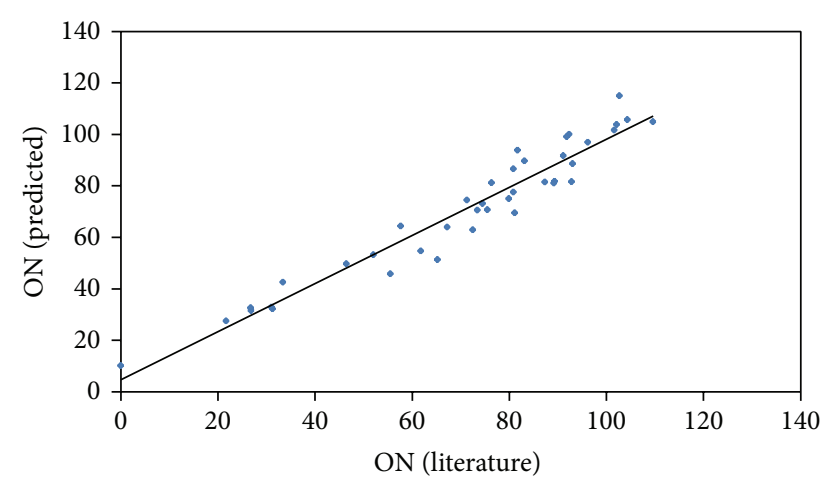

FIgURE 2: Linear relationship between the predicted and the literature octane number for the training set.

be 0.932 . The standard error expresses the variation of the residuals or the variation about the regression line. Thus the standard error measures the model error; it is equal to 7.76 , where $F=53.22$ and significance $F=5.687 \mathrm{E}-16$. So, the regression model is considered to be highly significant.
Table 3 shows regression coefficients $B$, standard errors, $t$-stat, $P$ value (significance), and confidence intervals of the linear regression models $\left(R^{2}=0.932, s=7.76, F=53.22\right.$, and Sig. $=5.687 \mathrm{E}-16)$. The $t$-values and $P$ values indicate that the proposed 8 descriptors are relevant to predict $\mathrm{ON}$. Table 3 also defines the confidence intervals for regression coefficients $B_{i}$ of descriptors. Positive values in the regression coefficient indicate that the descriptors contribute positively to the value of octane number. Negative values indicate that the greater the value of the descriptor, the lower the value of octane number.

The $t$-stat measures the statistical significance of the regression coefficients. The higher $t$-stat values correspond to the relatively more significant regression coefficients. $P$ values indicate that the model is statistically significant. The resulting correlation model for prediction of the physical properties of interest is in the form of the following (1). The predicted $(\mathrm{ON})$ gives linear relationship with the literature $(\mathrm{ON})$ as shown in Figure 2.

Consider

$$
\begin{aligned}
\text { Octane number }= & -(193.53 \pm 319.19) \\
& +(1.47 \pm 1.01) M \\
& -(53.06 \pm 31.47) E_{H} \\
& -(8.67 \pm 2.73) B_{P} \\
& -(24.94 \pm 19.44) M_{R} \\
& -(50.52 \pm 26.92) \log P \\
& +(4.33 \pm 3.09) C_{P} \\
& +(3.72 \pm 2.04) C_{V} \\
& +(5.17 \pm 2.08) C_{T} .
\end{aligned}
$$

4.2. Validation Set. In order to test the predictive power of the obtained model (1), the regression coefficients $\beta_{i}$ shown in Table 3 are used to predict the octane number for the rest of molecules given in Table 4. The obtained results of validation set are pronounced to be good which are characterized by $R^{2} C_{V}$ value of 0.94 and a standard error of 6.96. It is clear from Figure 3 that the predicted values of $\mathrm{ON}$ are in good agreement with the literature value. 
TABLE 3: Regression coefficients $\beta_{i}$, standard errors $s, t$-test, and statistic and confidence intervals of the best linear regression models $\left(R^{2}=\right.$ $0.932, s=7.763, F=53.218$, and significance $F=5.69 E-16$ ).

\begin{tabular}{lcccccc}
\hline & $\beta_{i}$ & $s$ & $t$ stat & $P$ value & Lower 95\% & Upper 95\% \\
\hline Intercept & -193.35 & 157.94 & -1.224 & $2.301 E-01$ & -515.47 & 0.45 \\
$M$ & 1.47 & 0.50 & 2.928 & $6.334 E-03$ & -84.81 & -21.30 \\
$E_{H}$ & -53.06 & 15.57 & -3.407 & $1.835 E-03$ & -11.43 & -5.92 \\
$B_{P}$ & -8.67 & 1.35 & -6.419 & $3.746 E-07$ & -44.56 & -5.31 \\
$M_{R}$ & -24.94 & 9.62 & -2.592 & $1.444 E-02$ & 1.22 & -23.35 \\
$\log P$ & -50.52 & 13.32 & -3.793 & $6.475 E-04$ & $7.968 E-03$ & 7.67 \\
$C_{P}$ & 4.33 & 1.53 & 2.837 & $8.488 E-04$ & 3.07 & 7.78 \\
$C_{V}$ & 3.72 & 1.01 & 3.694 & $2.083 E-05$ & & 3.28 \\
$C_{T}$ & 5.17 & 1.03 & 5.011 & &
\end{tabular}

TABLE 4: Cross-validation set of hydrocarbons with their molecular mass $M$, hydration energy $E_{H}$, boiling point $B_{P}$, molar refractivity $M_{R}$, octanol/water distribution coefficient $\log P$, critical pressure $C_{P}$, critical volume $C_{V}$, critical temperature $C_{T}$, and the literature octane number $\mathrm{ON}$.

\begin{tabular}{|c|c|c|c|c|c|c|c|c|c|c|c|}
\hline & Name & $M$ & $E_{H}$ & $B_{P}$ & $M_{R}$ & $\log P$ & $C_{P}$ & $C_{V}$ & $C_{T}$ & $\mathrm{ON}(\mathrm{L})$ & $\mathrm{On}(\mathrm{P})$ \\
\hline 41 & 2,2-Dimethylheptane & 128.26 & 4.22 & 393.07 & 43.03 & 4.55 & 23.50 & 528.50 & 562.65 & 50.30 & 37.89 \\
\hline 42 & Diethylpentane & 128.26 & 3.57 & 393.07 & 43.03 & 4.55 & 23.50 & 528.50 & 562.65 & 84.00 & 72.38 \\
\hline 43 & 2,2-Dimethyl-3-ethylpentane & 128.26 & 3.72 & 378.89 & 42.98 & 4.29 & 23.68 & 522.50 & 546.31 & 112.10 & 95.75 \\
\hline 44 & 2,4-Dimethyl-3-ethylpentane & 128.26 & 3.68 & 373.95 & 43.05 & 3.70 & 23.61 & 521.50 & 535.33 & 105.30 & 107.98 \\
\hline 45 & 2,2,3,3-Tetramethylpentane & 128.26 & 3.65 & 369.38 & 42.86 & 4.64 & 23.94 & 517.50 & 540.70 & 116.80 & 120.77 \\
\hline 46 & 3,3,4-Trimethylheptane & 142.28 & 4.06 & 402.24 & 47.58 & 4.75 & 21.61 & 578.50 & 569.39 & 86.40 & 76.74 \\
\hline 47 & 2,2,3,3-Tetramethylhexane & 142.28 & 3.92 & 393.09 & 47.46 & 5.09 & 21.84 & 573.50 & 564.30 & 112.80 & 105.42 \\
\hline 48 & Cyclohexane & 84.16 & 2.49 & 362.90 & 27.61 & 2.74 & 41.30 & 305.50 & 568.54 & 84.00 & 79.63 \\
\hline 49 & Methylcyclohexane & 98.19 & 2.66 & 380.01 & 32.16 & 2.94 & 35.22 & 360.50 & 583.00 & 73.80 & 72.53 \\
\hline 50 & Ethylcyclohexane & 112.22 & 2.89 & 403.32 & 36.76 & 3.40 & 31.53 & 416.50 & 604.85 & 46.50 & 46.35 \\
\hline 51 & 1,1-Dimethylcyclohexane & 112.22 & 2.92 & 391.13 & 36.63 & 3.74 & 33.18 & 414.50 & 595.58 & 87.30 & 88.32 \\
\hline 52 & 1,2-Dimethylcyclohexane & 112.22 & 2.83 & 396.66 & 36.70 & 3.14 & 30.39 & 415.50 & 596.67 & 80.90 & 70.98 \\
\hline 53 & 1,3-Dimethylcyclohexane & 112.22 & 2.93 & 396.66 & 36.70 & 3.14 & 30.39 & 415.50 & 596.67 & 69.30 & 65.67 \\
\hline 54 & 1,4-Dimethylcyclohexane & 112.22 & 2.83 & 396.66 & 36.70 & 3.14 & 30.39 & 415.50 & 596.67 & 67.70 & 70.98 \\
\hline 55 & n-Propylcyclohexane & 126.24 & 3.19 & 425.73 & 41.36 & 3.85 & 28.38 & 472.50 & 625.08 & 17.80 & 18.71 \\
\hline 56 & Isopropylcyclohexane & 126.24 & 2.99 & 412.33 & 41.30 & 3.60 & 28.63 & 466.50 & 610.27 & 62.80 & 61.85 \\
\hline 57 & 1-Methyl-1-ethylcyclohexane & 126.24 & 3.06 & 414.02 & 41.23 & 4.20 & 29.80 & 470.50 & 616.56 & 68.70 & 67.39 \\
\hline 58 & 1,1,2-Trimethylcyclohexane & 126.24 & 3.00 & 407.48 & 41.18 & 3.94 & 28.75 & 469.50 & 608.63 & 95.70 & 92.41 \\
\hline 59 & 1,2,3-Trimethylcyclohexane & 126.24 & 2.90 & 412.85 & 41.25 & 3.35 & 26.49 & 470.50 & 609.62 & 84.80 & 78.26 \\
\hline 60 & 1,2,4-Trimethylcyclohexane & 126.24 & 3.00 & 412.85 & 41.25 & 3.35 & 26.49 & 470.50 & 609.62 & 72.90 & 72.96 \\
\hline 61 & 1,3,5-Trimethylcyclohexane & 126.24 & 3.00 & 412.85 & 41.25 & 3.35 & 26.49 & 470.50 & 609.62 & 63.80 & 72.96 \\
\hline 62 & Isobutylcyclohexane & 140.27 & 3.30 & 434.38 & 45.91 & 4.06 & 25.90 & 522.50 & 630.00 & 33.70 & 35.30 \\
\hline 63 & sec-Butylcyclohexane & 140.27 & 3.20 & 434.38 & 45.91 & 4.06 & 25.90 & 522.50 & 630.00 & 51.00 & 40.60 \\
\hline 64 & 1-Isopropyl-4-methylcyclohexane & 140.20 & 3.10 & 428.08 & 45.85 & 3.80 & 25.05 & 521.50 & 622.54 & 67.30 & 69.11 \\
\hline 65 & 1-Methyl-2-n-propylcyclohexane & 140.20 & 3.40 & 441.10 & 45.91 & 4.06 & 24.85 & 527.50 & 636.66 & 29.90 & 20.11 \\
\hline
\end{tabular}

The linear correlation between the experimental and predicted values of octane numbers $\mathrm{ON}$ is graphically represented in Figure 3.

We come to conclusion that in model (1), as the energy of hydration energy $E_{H}$, boiling point $B_{P}$, molar refractivity
$M_{R}$, and octanol/water distribution coefficient $\log P$ increase, octane number decreases. However an increase in the values of other descriptors, namely, molar mass $M$, critical pressure $C_{P}$, critical volume, $C_{V}$, and critical temperature $C_{T}$, increases the value of the octane number. 


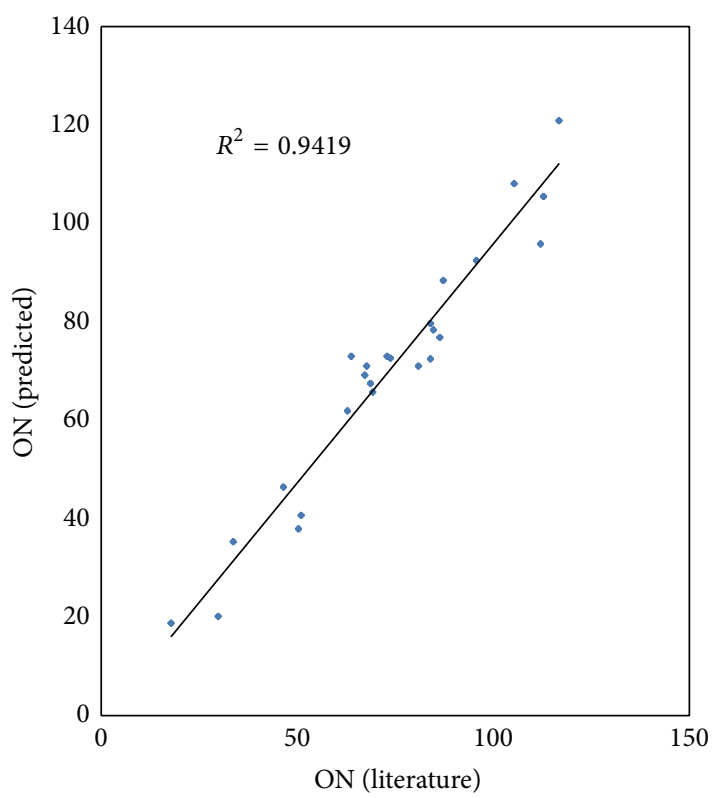

FIGURE 3: Linear relationship between the literature and predicted values of the octane number for the validation set. $R_{C_{V}}^{2}=0.9419$.

\section{Conflict of Interests}

The authors declare that there is no conflict of interests regarding the publication of this paper.

\section{References}

[1] Annual Book of ASTM Standards, vol. 05.04, 1985.

[2] A. Perdih and F. Perdih, "Chemical interpretation of octane number," Acta Chimica Slovenica, vol. 53, no. 3, pp. 306-315, 2006.

[3] T. A. Albahri, "Structural group contribution method for predicting the octane number of pure hydrocarbon liquids," Industrial and Engineering Chemistry Research, vol. 42, no. 3, pp. 657662, 2003.

[4] N. Nikolaou, C. E. Papadopoulos, I. A. Gaglias, and K. G. Pitarakis, "A new non-linear calculation method of isomerisation gasoline research octane number based on gas chromatographic data," Fuel, vol. 83, no. 4-5, pp. 517-523, 2004.

[5] H. Chung, H. Lee, and C.-H. Jun, "Determination of research octane number using NIR spectral data and ridge regression," Bulletin of the Korean Chemical Society, vol. 22, no. 1, pp. 37-42, 2001.

[6] H. Hosoya, "Chemical meaning of octane number analyzed by topological indices," Croatica Chemica Acta, vol. 75, no. 2, pp. 433-445, 2002.

[7] J. J. Kelly, C. H. Barlow, T. M. Jinguji, and J. B. Callis, "Prediction of gasoline octane numbers by near infrared spectroscopy in the spectral range 680-1235 nm," Analytical Chemistry, vol. 61, no. 4, pp. 313-320, 1989.

[8] R. Meusinger and R. Moros, "Determination of octane numbers of gasoline compounds from their chemical structure by $13 \mathrm{C}$ NMR spectroscopy and neural networks," Fuel, vol. 80, no. 5, pp. 613-621, 2001.
[9] M. A. Al-Ghouti, Y. S. Al-Degs, and M. Amer, "Determination of motor gasoline adulteration using FTIR spectroscopy and multivariate calibration," Talanta, vol. 76, no. 5, pp. 1105-1112, 2008.

[10] N. Pasadakis, V. Gaganis, and C. Foteinopoulos, "Octane number prediction for gasoline blends," Fuel Processing Technology, vol. 87, no. 6, pp. 505-509, 2006.

[11] J. Dcvillers, Comparative Qsar, Taylor \& Francis, Philadelphia, $\mathrm{Pa}, \mathrm{USA}, 1998$.

[12] L. B. Kiel and I. H. Hall, Molecular Structure Description, Academic Press, New York, NY, USA, 1999.

[13] R. C. Reid, J. M. Prausnitz, and B. E. Polling, The Properties of Gases and Liquids, McGraw-Hill, New York, NY, USA, 1987.

[14] M. M. C. Ferreira, "Multivariate QSAR," Journal of the Brazilian Chemical Society, vol. 13, no. 6, pp. 742-753, 2002.

[15] T. Abdel-Moghny, E. Ahmed Gad, and Y. Mostafa, "Effect of interfacially active fractions of some Egyptian crude oils on their emulsion stability," Journal of Dispersion Science and Technology, vol. 27, no. 1, pp. 133-141, 2006.

[16] E. A. M. Gad, "QSPR for nonionic surfactants," Journal of Dispersion Science and Technology, vol. 28, no. 2, pp. 231-237, 2007.

[17] E. A. M. Gad and K. S. Khairou, "QSPR for HLB of nonionic surfactants based on polyoxyethylene group," Journal of Dispersion Science and Technology, vol. 29, no. 7, pp. 940-947, 2008.

[18] E. A. Smolenskii, A. N. Ryzhov, V. M. Bavykin, T. N. Myshenkova, and A. L. Lapidus, "Octane numbers (ONs) of hydrocarbons: a QSPR study using optimal topological indices for the topological equivalents of the ONs," Russian Chemical Bulletin, vol. 56, no. 9, pp. 1681-1693, 2007. 

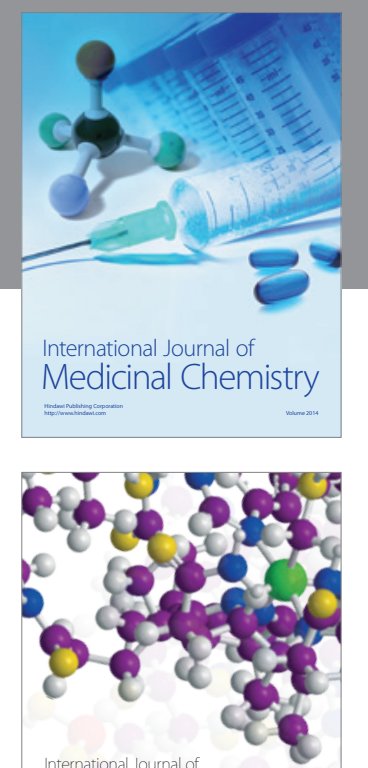

\section{Carbohydrate} Chemistry

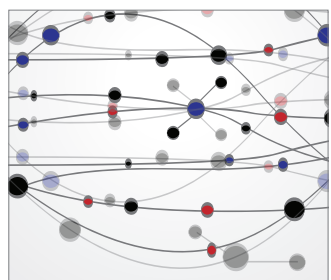

The Scientific World Journal
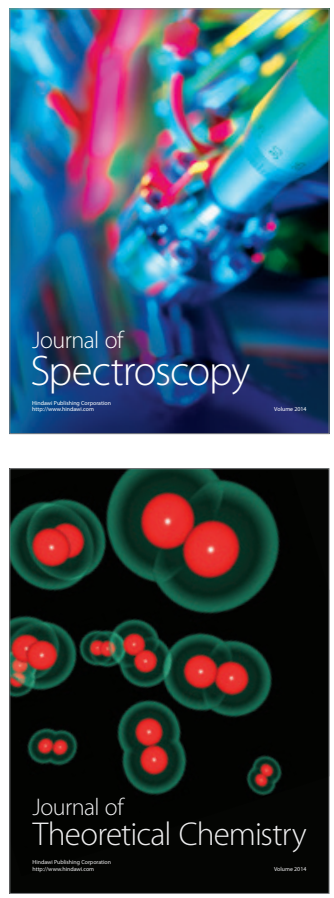
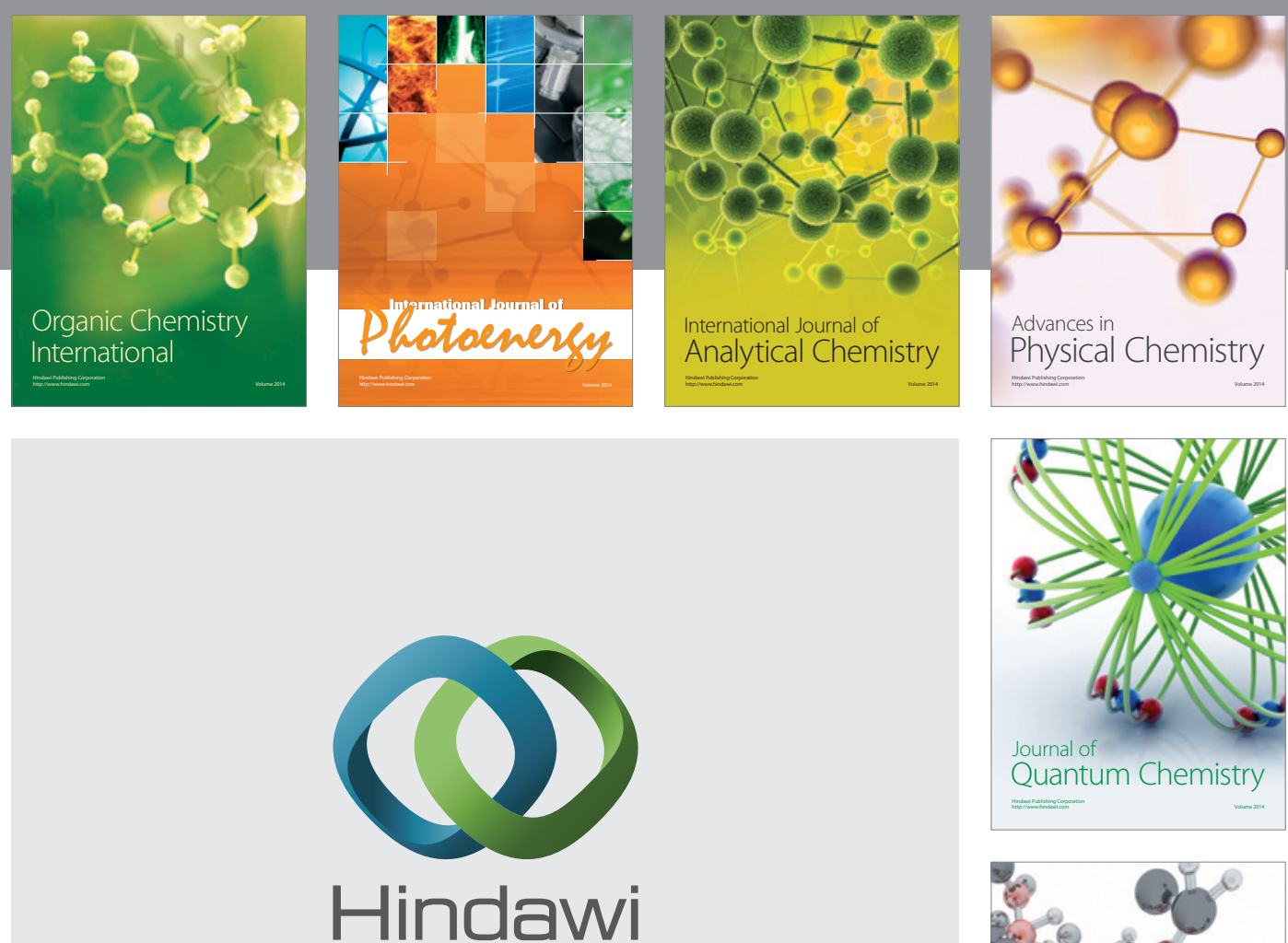

Submit your manuscripts at

http://www.hindawi.com

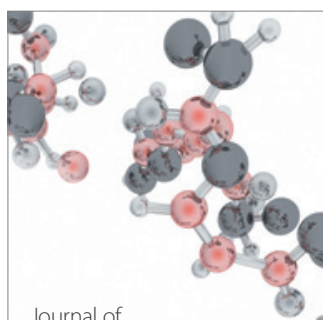

Analytical Methods

in Chemistry

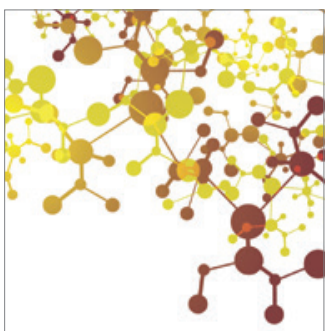

Journal of

Applied Chemistry

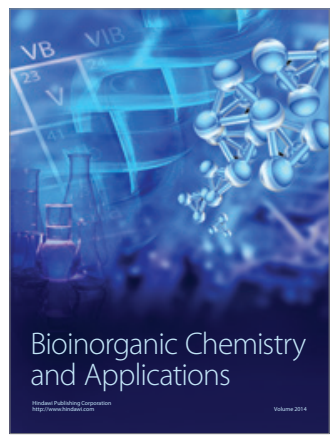

Inorganic Chemistry
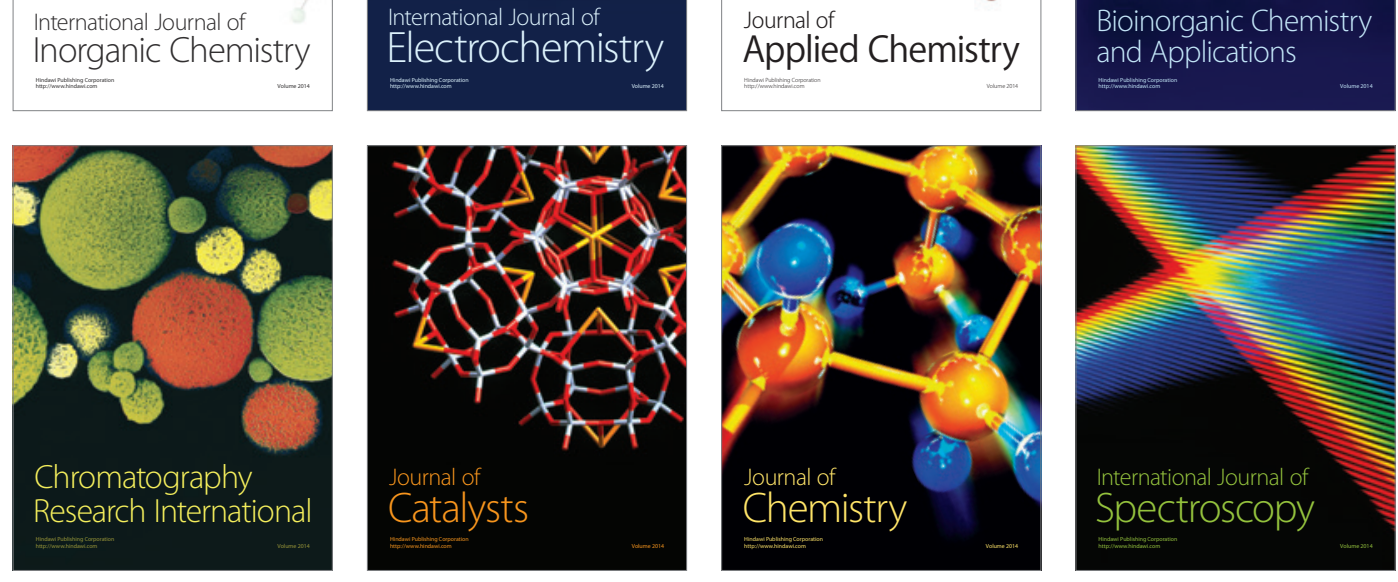